\title{
En los comienzos de la empresa pública argentina: la Administración de los Ferrocarriles del Estado y las Obras Sanitarias de la Nación antes de 1930
}

\section{At the beginning of public enterprise in Argentina: Administración de los Ferrocarriles del Estado and Obras Sanitarias de la Nación before 1930}

\author{
ANDRÉS M. REGALSKY \\ CONICET y Universidad Nacional de Tres de Febrero, Argentina \\ ELENA SALERNO \\ Universidad Nacional de Tres de Febrero, Argentina
}

\begin{abstract}
RESUMEN
En este trabajo se analiza el surgimiento y desarrollo hasta 1930 de dos de las primeras empresas públicas argentinas organizadas en el

siglo XX: la Administración General de los

Ferrocarriles del Estado (AGFE) y las Obras Sanitarias de la Nación (OSN), creadas en 1909 y

1912 respectivamente. Se examina comparativamente la trayectoria de ambas entidades, sus orígenes en el último tercio del siglo XIX y el proceso a través del cual lograron adquirir un cierto carácter autónomo. En ese sentido se examina el proceso de inversiones -

vinculado con el ciclo de auge del gasto y la

inversión pública por parte del Estado nacional-, los divergentes resultados obtenidos en materia de rentabilidad y la conformación, en ambas entidades, de un elenco de funcionarios que tendió a formar una burocracia técnica estatal, algunas de cuyas figuras llegaron a ocupar los más altos cargos de conducción.
\end{abstract}

PALABRAS CLAVE: Empresa pública, Ferrocarriles, Saneamiento, Argentina

\section{ABSTRACT}

In this work we examine the emergence and development until 1930 of two of the first Argentine public enterprises organised during the $20^{\text {th }}$ century: Administración General de los Ferrocarriles del Estado (State Railways National Administration) and Obras Sanitarias de la Nación (Water and Drainage National Works), created in 1909 and 1912 respectively. The trajectory of both entities is examined and compared, as well as their origins during the last third of the $19^{\text {th }}$ century and the process through which they managed to achieve a certain autonomous character. In this sense the investment process connected with the cycle of the great increase in expenditure and public investment by the Stateis examined in relation to the rentability achieved and the conformation, in both entities, of a staff of public servants that tended to shape a State technical burocracy, some of whose members arrived to the highest leading places afterwards.

KEY WORDS: Public Enterprise, Railways, Water and Drainage, Argentina

JEL Codes: N46, N76, N86 


\section{Introducción ${ }^{1}$}

$\mathrm{E}$ n este trabajo, que forma parte de una investigación más amplia sobre el comportamiento de la inversión pública en Argentina en los primeros decenios del siglo XX, nos proponemos analizar el surgimiento en ese período de dos de las primeras empresas públicas organizadas desde el Estado nacional: la Administración General de los Ferrocarriles del Estado (AGFE) y las Obras Sanitarias de la Nación (OSN), creadas en 1909 y 1912, respectivamente. Ambas empresas que, como se verá, tuvieron en algunos aspectos una evolución bien diferente, coincidieron en gestarse tras un largo período de incubación — a través de diversos organismos estatales- al menos desde el último tercio del siglo XIX, lograron al cabo de ese proceso adquirir un cierto carácter autónomo y sus elencos de funcionarios tendieron a formar una burocracia técnica estatal, algunas de cuyas figuras llegaron a ocupar los más altos cargos de conducción.

El trabajo abarca un período que se inicia con la fase de auge del modelo agroexportador y conoce luego diversos avatares, como el estallido de la I Guerra Mundial, el retorno de una cierta prosperidad sujeta a diversas fluctuaciones durante los años veinte y la gran crisis que comienza en 1929, aunque sus efectos se harían sentir con mayor plenitud en los años siguientes. En el transcurso de estas tres décadas un rasgo mantuvo una gran continuidad: el sostenido crecimiento del gasto público, que permaneció en niveles elevados aún en momentos de severas dificultades externas y caída de ingresos, a través de una creciente articulación con el mercado local de capitales ${ }^{2}$.

Esta expansión del gasto público fue simultánea con un proceso de ampliación y transformaciones del aparato estatal que no reconoció pausas desde los tiempos de la "organización nacional" (1852-1880). Uno de los objetivos permanentes fue el de afianzar la presencia del Estado en todo el territorio nacional, no sólo a través del monopolio de la fuerza, sino también de diversos emprendimientos tales como escuelas, correos y otros vinculados más directamente con el desarrollo económico, como el fomento agrícola y la construcción de obras públicas ${ }^{3}$.

[Fecha de recepción del original, mayo de 2007. Versión definitiva, enero de 2008]

1 Queremos agradecer las sugerencias realizadas por los evaluadores anónimos de Investigaciones de Historia Económica.

2 Véase sobre este período Díaz Alejandro (1975) y Cortés Conde (1997). Desde una perspectiva más ligada a la política económica, Cortés Conde (2005) y Gerchunoff y Llach (2003). En relación con la evolución de las finanzas, Soares (1932). Una sugestiva visión comparativa con otros países latinoamericanos en Díaz Fuentes (1994).

3 Sobre la expansión temprana del gasto público a partir de 1862 y su orientación al desarrollo económico, véase Cortés Conde (1989); con respecto a la consolidación del Estado nacional y sus nuevas funciones, Oszlak (1982). La acción estatal dirigida a la creación de bienes públicos también ha sido señalada por la historiografía política, en relación con el surgimiento de un reformismo liberal. Véanse Botana (1998) y Zimmermann (1995). 
Para la gestión de este accionar se crearon diversos organismos especializados: por un lado, entes administrativos fuertemente jerarquizados que atendían los gastos militares; por el otro, agencias de fomento estatal y las primeras empresas públicas $^{4}$. Aunque AGFE y OSN funcionaron desde cierto punto de vista como agencias de fomento, por su carácter autónomo y la posibilidad de generar recursos y administrarlos, pueden considerarse los primeros casos de empresa estatal, que precedieron como tales a otra que tomaría mayor importancia en las visiones retrospectivas, la de los Yacimientos Petrolíferos Fiscales (YPF) ${ }^{5}$.

La empresa pública ha sido asociada corrientemente a una etapa posterior en la Argentina, la del Estado intervencionista o "Estado empresario". Es importante consignar, sin embargo, que los comienzos de las tres empresas enunciadas más arriba se ubican en un momento previo, en lo que podría denominarse la fase tardía del Estado liberal 6 . En un trabajo pionero se ha esbozado una periodización muy útil para comprender las creaciones de esta etapa, que a su vez pueden ser puestas en la perspectiva del movimiento de formación de empresas públicas que se estaba generando en el mundo occidental. No obstante, es poco lo que se ha explorado hasta ahora sobre las características, logros y debilidades de estas organizaciones en su fase inicial que ayuden a entender los problemas observados posteriormente. Es en esta dirección en la que profundiza este trabajo ${ }^{7}$.

\section{Gasto público e inversiones: una aproximación al gasto en ferroca- rriles y obras sanitarias de la nación}

Como quedó dicho, el aumento del gasto público - y su correlato, la ampliación del aparato estatal- fue uno de los fenómenos sobresalientes del período, y sentó las bases sobre las que se verificó el surgimiento de la empresa pública en esos años. El examen de la composición del gasto y, particularmente, la incidencia en el mismo de la inversión u obra pública, puede aportar algunas claves para entender este proceso.

4 Sobre las primeras agencias de fomento, Marichal (1988). Sobre los primeros antecedentes de la empresa pública argentina en el siglo XIX, Schvarzer y Gómez (2006).

5 Para este último caso, véanse Solberg (1982) y, sobre todo, Gadano (2006). Formada en 1907, asumió características de empresa hacia los años veinte.

6 En este sentido, nuestro análisis converge con los planteamientos de Topik (1987) sobre el elevado activismo económico del Estado antes de 1930, a diferencia de lo que se suele suponer habitualmente.

7 Schvarzer (1979). Para la empresa pública en España y en Europa, Comín y Martín Aceña (1991) y Comín y Díaz Fuentes (2004). Sobre el papel de la empresa pública en los servicios públicos e infraestructura, Foreman-Peck y Millward (1994) y Hassan (1995). 
Los datos recopilados por la Contaduría General de la Nación, si bien adolecen de algunos desfases importantes respecto de las cuentas que llevaban las diversas reparticiones, permiten visualizar año a año la distribución global y detallada de esas erogaciones ${ }^{8}$.

Al comenzar el período, los gastos en obras públicas se cifraban en unos 20 millones de pesos moneda nacional, equivalentes a un 10 por 100 del gasto total. A partir de 1905, el comportamiento de esta variable resultó uno de los componentes más activos en el aumento general del gasto (Cuadro 1). En efecto, mientras este último aumentó unas 2,3 veces hasta 1910-1914, el correspondiente al Ministerio de Obras Públicas, sumado a la partida de los "Trabajos Públicos", lo hizo 4,5 veces, situándose en 88 millones de pesos (un 21,4 por 100 del total) y con un valor máximo de 100 millones para 1909-1911 (y 25 por 100 de participación, récord absoluto para el período).

La estabilización del gasto durante la guerra (en términos nominales, dados los fuertes aumentos de precios de esos años) estuvo, a su vez, acompañada de una abrupta retracción de la obra pública, descendiendo su participación a un 9 por 100 . A partir de 1920, volvió a apreciarse una reactivación del total de erogaciones, cuyo valor entre 1925 y 1929 más que duplicó el de 1910-1914. El monto destinado a obras y trabajos públicos retomó y superó entonces los niveles de preguerra, con 130 millones de pesos y una participación relativa del 15 por $100^{9}$.

Ahora bien, una parte sustancial de la inversión pública se destinó a los dos rubros que hemos seleccionado, ferrocarriles y saneamiento. El seguimiento de estas inversiones nos permite observar el papel central que jugaron en el comportamiento del conjunto. Cualitativamente tuvieron un rol protagonista en la ampliación del aparato estatal. Los ferrocarriles aparecían como una de las herramientas más potentes para afirmar la presencia del Estado en las regiones más alejadas. Esta presencia también se consolidaba a través del vasto plan de saneamiento en la gran metrópoli en que se había convertido la ciudad de Buenos Aires, así como de la provisión de los servicios básicos en un gran número de pueblos y ciudades en todo el país.

La suma de ambos rubros, que apenas superaba los 5 millones de pesos en 19001904 (un cuarto de la inversión total), pasó en 1910-1914 a más de 40 millones. Desde 1905, inclusive, absorbió la mitad de lo destinado a toda la obra pública. Inversamente, al bajar el gasto entre 1915 y 1919, su peso quedó reducido a un 17 por 100 y un nivel absoluto muy similar al del punto de partida. A partir de 1920, con la reactivación del gasto, ambos rubros volvieron nuevamente a subir, ubicándose su par-

8 Para una visión crítica sobre las cuentas presentadas por los distintos organismos, véase el informe del contador Mauricio Greffier, en Contaduría General de la Nación (1929), tomo. 1, pp. 1288-1303.

Sobre esta evolución pueden consultarse Regalsky y Salerno (2005) y Regalsky (1998). 


\section{CUADRO 1}

GASTO PÚBLICO TOTAL * Y GASTO PÚBLICO EN OBRAS PÚBLICAS,

FERROCARRILES Y SANEAMIENTO, 1900-1929

(medias quinquenales, miles de pesos moneda nacional)

\begin{tabular}{ccccccccc}
\hline Año & $\mathbf{( 1 )}$ & $\mathbf{( 2 )}$ & $\mathbf{( 2 ) / ( \mathbf { 1 } ) \times \mathbf { 1 0 0 }}$ & $\mathbf{( 3 )}$ & $\mathbf{( 3 ) / ( 2 ) \times 1 0 0}$ & $\mathbf{( 4 )}$ & $\mathbf{4}) /(\mathbf{2}) \times \mathbf{1 0 0}$ & $\mathbf{( 3 ) + ( 4 ) / ( 2 ) \times 1 0 0}$ \\
\hline $\mathbf{1 9 0 0 - 1 9 0 4}$ & 178.250 & 18.946 & 10,6 & 3.875 & 20,5 & 1.398 & 7,4 & 27,8 \\
$\mathbf{1 9 0 5 - 1 9 0 9}$ & 276.618 & 44.606 & 16,1 & 19.598 & 43,9 & 4.478 & 10,0 & 54,0 \\
$\mathbf{1 9 1 0 - 1 9 1 4}$ & 411.020 & 88.010 & 21,4 & 33.518 & 38,1 & 7.507 & 8,5 & 46,6 \\
$\mathbf{1 9 1 5 - 1 9 1 9}$ & 402.622 & 36.371 & 9,0 & 5.244 & 14,4 & 1.210 & 3,3 & 17,7 \\
$\mathbf{1 9 2 0 - 1 9 2 4}$ & 593.223 & 76.677 & 12,9 & 22.704 & 29,6 & 7.380 & 9,6 & 39,2 \\
$\mathbf{1 9 2 5 - 1 9 2 9}$ & 846.514 & 129.509 & 15,3 & 24.950 & 19,3 & 26.344 & 20,3 & 39,6 \\
\hline
\end{tabular}

$\left(^{*}\right)$ Se han deducido del gasto total las sumas destinadas al rescate o conversión de la deuda pública en 1905 (84,2 millones) y 1927 (133 millones), ya que sólo implicaron un movimiento entre distintas partidas del uso del crédito.

(1) Gasto Total.

(2) Obras Públicas.

(3) Ferrocarriles.

(4) Saneamiento.

Fuentes: Ministerio de Hacienda (1900-1911) y Contaduría General de la Nación (1912-29).

ticipación en el 40 por 100, mientras su monto absoluto se situaba en más de 50 millones de pesos (Cuadro 1).

De los dos, la inversión ferroviaria fue claramente mayoritaria. En los años previos a 1914 daba cuenta por sí sola del 40 por 100 de la obra pública. Después de 1914 su monto mermó notablemente, al punto de ser superada por las inversiones en saneamiento en 1925-1929.

\section{El surgimiento de la AGFE y el crecimiento de la red de los ferroca- rriles del Estado}

La intervención del Estado nacional en la construcción ferroviaria tuvo lugar a partir del último tercio del siglo XIX, procurando llevar el servicio al interior del país en aquellos recorridos que no interesaban a las compañías privadas existentes, todas ellas de capitales británicos. En 1867, el gobierno liberal de Bartolomé Mitre ordenó el estudio de un ferrocarril de Villa María a Río Cuarto, luego denominado Andino, y que habría de proseguir hacia el oeste hasta las provincias de Mendoza y San Juan. La inauguración oficial de ese primer tramo, en 1873, dio lugar a la primera adminis- 
tración estatal, seguida en 1876 por la del Central Norte, entre las ciudades de Córdoba y Tucumán. Ambas líneas no tenían acceso a las ciudades del litoral sino era a través del Central Argentino, de propiedad británica, que enlazaba Córdoba con Rosario. Sucesivas ampliaciones hacia el oeste y hacia el norte, particularmente durante la presidencia del general Roca (1880-1886), fueron llevando la longitud de esta red estatal a unos 1.900 kilómetros en 1886, lo que sumado a las líneas de propiedad de los estados provinciales (el Ferrocarril Oeste en la provincia de Buenos Aires, y el Ferrocarril de Santa Fe) equivalían a la mitad de la red ferroviaria existente ${ }^{10}$.

A partir de 1887, en un drástico viraje de la política seguida por las anteriores administraciones, el presidente Juárez Celman (1886-1890) dispuso la enajenación o arriendo de la casi totalidad de las líneas del Estado, política que fue seguida por los gobernadores provinciales (sobre los presidentes argentinos, véase el Anexo 1). De este modo, hacia 1890 la longitud manejada por el Estado se había reducido a unos 300 kilómetros. Ésta aumentaría al año siguiente a 1.000 kilómetros, con una serie de ramales dispersos en zonas periféricas que no llegaban a constituir una red ${ }^{11}$.

Las nuevas administraciones, tras la renuncia de Juárez Celman en 1890, tuvieron una visión crítica de la experiencia anterior y buscaron recrear la formación de un sistema ferroviario de propiedad oficial, con criterio de fomento hacia las zonas más rezagadas. En los años siguientes, el Estado retomó la administración de líneas dispersas y compró algunas líneas privadas fallidas. Con ello pudo comenzar a reconstituir una red estatal coherente, organizada en torno a tres líneas: el nuevo Central Norte, el Argentino del Norte y el Andino, que totalizaban 2.000 kilómetros $^{12}$. Entre 1900 y 1930, su extensión se ampliaría a casi 9.000 kilómetros, cubriendo los confines del norte y del sur del territorio nacional. Su participación en el total, que en 1890 apenas llegaba al 2,5 por 100, se ubicó a partir de 1900 y 1910 por encima del 12 por 100 y hacia 1930 alcanzaba el 22,6 por 100. Desde 1914, el dinamismo de las construcciones estatales contrastaba con la parálisis casi total de la actividad constructora por parte de las empresas privadas (véase el Cuadro 2).

10 El Ferrocarril Oeste, la primera línea construida en el país por un grupo de inversores locales, pasó a manos de la administración provincial en 1862 (Schvarzer y Gómez, 2006, p. 249). El Ferrocarril de Santa Fe a las Colonias, por su parte, fue construido por el gobierno de esa provincia desde 1882. Sobre este tema existe una amplia literatura clásica y reciente. Véanse Lewis (1983), Regalsky (2002), López (1991) y (1994) y, entre los clásicos, Scalabrini (1986 [1957]), Ortiz (1946) y Zalduendo (1975).

11 Sobre este proceso, junto a la bibliografía antes citada, véanse López (2000), pp. 338-341 y 370-399, y las diversas memorias oficiales: Departamento de Obras Públicas (1885-1888), vol. 1, p. 401 y vol. 3, pp. 159160; Dirección de los Ferrocarriles Nacionales (1891), p. 5; y Dirección General de Ferrocarriles (1892), pp. 51-52, 55. En 1890 el Estado nacional conservaba la línea de Chumbicha a Catamarca y un pequeño tramo del Andino, de Villa María a Villa Mercedes. En 1891 volvieron al Estado otras dos secciones, de Tucumán a Salta y Jujuy, y de Deán Funes a Chilecito.

12 En 1896-1897 fueron adquiridas dos compañías francesas, de San Cristóbal a Tucumán y de Villa Mercedes a La Toma. Regalsky (2002). 
CUADRO 2

LA EVOLUCIÓN DE LA RED FERROVIARIA ARGENTINA, 1890-1940

\begin{tabular}{lcrccc}
\hline Años & $\begin{array}{c}\text { Total red } \\
(\mathbf{K m})\end{array}$ & $\begin{array}{c}\text { Red } \\
(\mathbf{K m})\end{array}$ & $\begin{array}{c}\text { Porcentajes } \\
\text { sobre el total }\end{array}$ & $\begin{array}{c}\text { Capital realizado } \\
(\text { miles pesos oro) }\end{array}$ & $\begin{array}{c}\text { Capital/Km } \\
\text { (miles pesos oro) }\end{array}$ \\
\cline { 3 - 6 } & $12.606^{*}$ & 320 & 2,53 & $\mathrm{~s} / \mathrm{d}$ & $\mathrm{s} / \mathrm{d}$ \\
$\mathbf{1 8 9 0}$ & 14.029 & 1.026 & 7,32 & $\mathrm{~s} / \mathrm{d}$ & $\mathrm{s} / \mathrm{d}$ \\
$\mathbf{1 8 9 5}$ & 16.563 & 2.016 & 12,17 & 54.958 & 27 \\
$\mathbf{1 9 0 0}$ & 27.992 & 3.490 & 12,47 & 91.321 & 26 \\
$\mathbf{1 9 1 0}$ & 35.278 & 6.310 & 17,89 & $171.335^{\star *}$ & 27 \\
$\mathbf{1 9 2 0}$ & 39.799 & 8.979 & 22,56 & 335.489 & 37 \\
\hline $\mathbf{1 9 3 0}$ & &
\end{tabular}

$\left(^{*}\right)$ El dato de 1890 del total de la red corresponde al año 1891.

(s/d) Sin datos disponibles.

${ }^{* *}$ El dato sobre capital realizado en 1920 para los ferrocarriles estatales es de 1921.

$\left.{ }^{(* *}\right)$ La paridad oficial era de 1 peso oro $=2,2727$ pesos moneda nacional

Fuentes: Dirección General de Ferrocarriles (1892-1930).

El programa de ampliaciones desarrollado en este nuevo período comenzó a ser delineado hacia fines de la segunda presidencia de Roca (1898-1904). Impulsado por su ministro de Obras Públicas, Emilio Civit, preveía obras en las provincias del Noroeste, Cuyo y el Litoral, tendentes a extender y unificar el sistema, y a asegurar la conexión ferroviaria con Bolivia. Por otra parte, y a fin de superar la dependencia respecto de las líneas privadas con las que debía empalmar su tráfico, se preveía el acceso directo a los grandes puertos del litoral, Santa Fe, Rosario y Bahía Blanca.

Las administraciones siguientes mantuvieron la decisión de ampliar la red estatal, aunque difirieron en ciertos criterios y objetivos. Ramos Mexía, ministro de Obras Públicas de las administraciones de Figueroa Alcorta (1904-1910) y Sáenz Peña (1910-14), mantuvo como cabecera general de las líneas a Santa Fe, pero suprimió los proyectos de extensión a Rosario y Bahía Blanca, con el argumento de evitar la competencia con las empresas privadas. Por otro lado, hizo sumar otras obras en la Mesopotamia y en los Territorios Nacionales, así como nuevas conexiones con los países vecinos (Bolivia, Paraguay y Chile) para facilitar las relaciones comerciales ${ }^{13}$.

13 Véase Ministerio de Obras Públicas (1898-1912), así como Lacoste (2000), pp. 32-33; Palermo (2001); y Salerno (2003). 


\section{CUADRO 3}

DISTRIBUCIÓN DE LA INVERSIÓN PÚBLICA EN OBRAS FERROVIARIAS, 1900-1929

(miles de pesos)

\begin{tabular}{lcccrrr}
\hline \multicolumn{1}{c}{ Año } & 1900-1907 & 1908-1915 & 1916-1919 & 1920-1924 & 1925-1929 & 1900-1929 \\
\hline (1) Varios & - & 13.745 & - & - & 22.873 & 36.618 \\
(2) FF.CC en las provincias & 11.074 & 111.449 & 3.096 & 27.144 & 26.125 & 178.889 \\
(3) FF.CC de Fomento & - & 73.452 & 3.563 & 18.414 & 15.549 & 110.980 \\
(4) FF.CC a Bolivia & 24.588 & - & 100 & 4.333 & 9.715 & 38.737 \\
(5) FC. a Chile & & & & & & \\
(o de Huaytiquina) & 573 & - & - & 29.405 & 5.600 & 35.578 \\
(6) FF.CC Mesopotámicos & 729 & 18.928 & - & 6.550 & 8.045 & 34.253 \\
\hline (1) En 1908-1915, Ferrocarril de Córdoba al Noroeste, y en 1925-1929, obras sin discriminar. \\
(2) Santa Fe, Córdoba, San Luis, Mendoza, San Juan, La Rioja, Catamarca, Santiago del Estero, Tucumán, Salta y \\
Jujuy (excepto las obras de conexión con Bolivia), Cablecarril a Famatina y los pagos al Ferrocarril Sud por la línea \\
a Neuquén (se incluyen los estudios). \\
(3) Obras ferroviarias previstas por la Ley 5559 en los Territorios Nacionales de la Patagonia y del Chaco. \\
(4) Incluye la conexión por La Quiaca y la de Embarcación a Yacuiba. \\
(5) Futura línea de Salta a la frontera con Chile. \\
(6) Incluyen los fondos para la conexión de las líneas privadas con las de Paraguay. \\
\hline
\end{tabular}

Fuentes: Ministerio de Hacienda (1900-1911) y Contaduría General de la Nación (1912-1928).

En la década de los años veinte la mayor parte de las inversiones se destinó a la continuación y conclusión de estas obras, suspendidas después de 1914, y de otras anheladas desde larga data, y que contaban con estudios previos, como la conexión de Salta con Chile (Ferrocarril de Huaytiquina) y el segundo enlace ferroviario con Bolivia por Yacuiba ${ }^{14}$. Como se aprecia en el Cuadro 3, las obras que demandaron más inversiones en forma individual fueron las conexiones ferroviarias con los países vecinos, aunque tomadas en su conjunto las obras en las provincias, y luego las de los territorios nacionales, fueron mayoritarias.

El desarrollo de las obras no estuvo exento de avatares. La primera fase, hasta 1910, se verificó en un marco de escasa autonomía de las administraciones ferroviarias, superávit en la explotación y aceptable transparencia en la contabilidad de los fondos. Hacia 1897, la Dirección de Ferrocarriles Nacionales ${ }^{15}$ había dispuesto el

\footnotetext{
14 Pretto (1926), pp. 19-27, 34 y 98-99.

15 Dirección de Informaciones y Publicaciones Ferroviarias (1946).
} 
CUADRO 4

LÍNEAS DEL ESTADO EN 1897

\begin{tabular}{llll}
\hline \multicolumn{1}{c}{ Ferrocarril } & $\begin{array}{c}\text { Sede de la } \\
\text { Administración }\end{array}$ & Sección & Líneas \\
\hline Central Norte (FCCN) & Tucumán & $\begin{array}{l}\text { Norte } \\
\text { Sur }\end{array}$ & $\begin{array}{l}\text { Tucumán a Salta y Jujuy } \\
\text { Tucumán a San Cristóbal }\end{array}$ \\
\hline Argentino del Norte (FCAN) & Cruz del Eje & $\begin{array}{l}\text { La Rioja } \\
\text { Catamarca }\end{array}$ & $\begin{array}{l}\text { Deán Funes a Chilecito } \\
\text { Chumbicha a Catamarca }\end{array}$ \\
\hline Andino (FCA) & Río Cuarto & & $\begin{array}{l}\text { Villa María a Villa Mercedes } \\
\text { Villa Mercedes a La Toma }\end{array}$ \\
\hline
\end{tabular}

Fuentes: Resolución del 5/11/1897. Dirección de Informaciones y Publicaciones Ferroviarias (1946), pp. 126-127.

reordenamiento de los ramales y de las respectivas denominaciones, tal y como se muestra en el Cuadro 4. Cada línea contaba con su propia administración, que dependía directamente del Ministerio del Interior y luego del de Obras Públicas. Desde 1894 fueron incorporados explícitamente a la ley de presupuesto, a través de la cual recibían una asignación de fondos para la explotación y las inversiones, estando obligadas a depositar su recaudación ante la Tesorería General ${ }^{16}$.

Tras la muerte del presidente Quintana, en marzo de 1906, y la asunción de su vicepresidente, Figueroa Alcorta, sobrevino un profundo cambio en las políticas del gobierno. En el área de Obras Públicas se estableció una nueva organización interna, transformando a la Dirección General de Vías de Comunicaciones (DGVC) en Dirección General de Ferrocarriles (DGF). En principio esta nueva Dirección tomó a su cargo la explotación técnica y comercial de los ferrocarriles, sin menoscabo de las administraciones particulares de cada línea que funcionaban en las sedes mencionadas ${ }^{17}$. De este modo, combinaba las funciones de regulador, para toda la actividad, con las de la administración de los Ferrocarriles del Estado.

La idea de una oficina específica encargada de los ferrocarriles estatales tomó forma en un proyecto de ley de 1907, que proponía crearla dentro del ámbito de la

16 En 1900, el Congreso autorizó a los administradores a invertir el excedente del producto de explotación en las mismas líneas, pero conservó el procedimiento anterior, que permitía conocer el movimiento de ingresos y salidas de los fondos.

17 Ministerio de Obras Públicas (1906-1907), p. 63. 


\section{CUADRO 5}

ADMINISTRADORES GENERALES Y MIEMBROS DEL CONSEJO DE ADMINISTRACIÓN DE AGFE, 1910-1930

\begin{tabular}{|c|c|c|c|c|}
\hline \multirow[b]{2}{*}{ Período } & \multirow{2}{*}{$\begin{array}{l}\text { Administrador } \\
\text { general }\end{array}$} & \multicolumn{3}{|c|}{ Consejo de Administración } \\
\hline & & $\begin{array}{l}\text { Ingeniero } \\
\text { Principal }\end{array}$ & $\begin{array}{l}\text { Jefe General } \\
\text { de Tráfico }\end{array}$ & $\begin{array}{l}\text { Contador } \\
\text { General }\end{array}$ \\
\hline $1910-1915$ & Ing. Miguel Iturbe & $\begin{array}{l}\text { Carlos M. Ramallo } \\
\text { Jorge Hainard }\end{array}$ & $\begin{array}{l}\text { Luis Rapelli } \\
\text { Carlos M. Ramallo }\end{array}$ & $\begin{array}{l}\text { Jaime Peter } \\
\text { Ernesto Manet }\end{array}$ \\
\hline $1915-1917$ & Ing. Luis Rapelli & Jorge Hainard & Carlos M. Ramallo & $\begin{array}{l}\text { Ernesto Manet } \\
\text { Manuel Palacio }\end{array}$ \\
\hline $1917-1918$ & $\begin{array}{l}\text { Ing. Carlos M. Ramallo } \\
\text { (Interino) }\end{array}$ & Jorge Hainard & Carlos M. Ramallo & Manuel Palacio \\
\hline $1918-1919$ & $\begin{array}{l}\text { Ing. Jorge Hainard } \\
\text { (Interino) }\end{array}$ & Jorge Hainard & & $\begin{array}{l}\text { Interventores: } \\
\text { Agustín Garimaldi } \\
\text { y Jorge L. Muñoz }\end{array}$ \\
\hline $1919-1920$ & $\begin{array}{l}\text { Cont. Jorge L. Muñoz } \\
\text { (Interino) }\end{array}$ & $\begin{array}{l}\text { Arturo Laferrière } \\
\text { Arturo Acevedo } \\
\text { (Interino) }\end{array}$ & & $\begin{array}{l}\text { Interventores: } \\
\text { Agustín Garimaldi } \\
\text { y Jorge L. Muñoz }\end{array}$ \\
\hline $\begin{array}{c}1920 \\
\text { (abr.-sep.) }\end{array}$ & $\begin{array}{l}\text { Ing. Arturo Acevedo } \\
\text { (Interino) }\end{array}$ & Arturo Acevedo & & $\begin{array}{l}\text { Interventor } \\
\text { Agustín Garimaldi }\end{array}$ \\
\hline $1920-1924$ & $\begin{array}{l}\text { Domingo Fernández } \\
\text { Beschtedt }\end{array}$ & Arturo Acevedo & Juan Raggio & Agustín Garimaldi \\
\hline $1924-1925$ & $\begin{array}{l}\text { Dr. Enrique S. Pérez } \\
\text { (Interino) }\end{array}$ & $\begin{array}{l}\text { Arturo Acevedo } \\
\text { Pablo Nogués } \\
\text { Haroldo B. Shaw }\end{array}$ & $\begin{array}{l}\text { Juan Raggio } \\
\text { Francisco Romero }\end{array}$ & $\begin{array}{l}\text { Agustín Garimaldi } \\
\text { Antonio Molinari }\end{array}$ \\
\hline $1925-1926$ & Dr. Enrique S. Pérez & & Francisco Romero & Antonio Molinari \\
\hline $\begin{array}{c}1926 \\
\text { (abr.-ago.) }\end{array}$ & $\begin{array}{l}\text { Ing. Augusto Krausse } \\
\text { Arnim (Interino) }\end{array}$ & José A. Marcet & Francisco Romero & Bartolomé Rossi \\
\hline 1926-1928 & $\begin{array}{l}\text { Ing. Augusto Krausse } \\
\text { Arnin }\end{array}$ & José A. Marcet & Francisco Romero & Bartolomé Rossi \\
\hline $1928-1930$ & Ing. Manuel J. Claps & José A. Marcet & Francisco Romero & $\begin{array}{l}\text { Interventor: } \\
\text { Nemesio Muntaabski }\end{array}$ \\
\hline
\end{tabular}


DGF. En 1908 un nuevo proyecto, en tanto mantenía las funciones de control a cargo de la Dirección General de Ferrocarriles, propuso la creación de una administración autónoma de las líneas, denominada Administración General de los Ferrocarriles del Estado (AGFE), que fue aprobada por el Congreso en septiembre de 1909.

La estructura de la nueva organización, que comenzó a funcionar desde mediados de 1910, estaba encabezada por un Administrador General de los Ferrocarriles del Estado, nombrado por el ejecutivo con acuerdo del Senado y un Consejo de Administración integrado por un Ingeniero Principal, un Jefe General de Tráfico y un Contador General, nombrados todos por el poder ejecutivo a propuesta del Administrador (Cuadro 5). El poder ejecutivo dispuso que los administradores que actuaban al frente de los dos ferrocarriles del Estado y sus funcionarios jerárquicos asumieran las nuevas responsabilidades. Así, se designó como primer Administrador a Miguel Iturbe, mientras que Carlos Ramallo, Jaime Peter y Luis Rapelli fueron designados Ingeniero Principal, Contador General y Superintendente General de Tráfico, respectivamente. Los ingenieros Iturbe, Ramallo y Rapelli habían sido administradores del Central Norte, entre otras funciones, y el Contador Peter había presidido el Argentino del Norte ${ }^{18}$.

Desde 1916, con la asunción en las primeras elecciones presidenciales libres de Hipólito Irigoyen (Unión Cívica Radical), se abrió una etapa mucho más compleja (véase Anexo 1). El poder ejecutivo mantuvo una relación conflictiva con el legislativo, y en particular con el Senado, controlado por la oposición conservadora, cuya legitimidad impugnaba por cuanto buena parte de sus miembros databan de antes de la aplicación de las nuevas normas electorales ${ }^{19}$. A medida que crecían las tensiones entre el ejecutivo radical y el Senado conservador, este último dilató la aprobación del nombramiento del Administrador General, hecho que obligó a designar administradores interinos, que fueron elegidos entre los funcionarios de carrera. En su mayoría, fueron promovidos ingenieros que trabajaban como Ingeniero Principal o Jefe General de Tráfico, y que retenían sus cargos durante el interinato. La única excepción fue Jorge J. Muñoz, que era contador y actuó como interventor en dicha área ${ }^{20}$.

Esto permite defender la hipótesis de que el Estado tenía una burocracia técnica y administrativa que tuvo continuidad más allá de los cambios administrativos y de gobierno. Recién a partir de 1920, con el nombramiento de Domingo Fernández Beschtedt, y luego de Enrique S. Pérez, se pudo acordar con el Congreso la designa-

18 Ramallo (1930), pp. 7-8 y 69. También, los expedientes de la Dirección General de Vías de Comunicación correspondientes a los ferrocarriles estatales en 1906. Museo Nacional Ferroviario, Archivo de la Dirección General de Ferrocarriles (ADGF, en adelante), Letra C, nº 02076, y Castaño (1914), pp. 7-8.

20 ACF, Actas del Consejo de Administración de los Ferrocarriles del Estado (ACF-AGFE), Años 1919-1930; y Decreto de 31/12/1909, Boletín Oficial de la República Argentina (BO, 1910), pp. 7-8. 
ción de administradores titulares, en ambos casos de neta extracción política ${ }^{21}$. Las complicaciones financieras en las que se vieron sucesivamente envueltos llevaron nuevamente a la presidencia de la AGFE a los ingenieros de carrera, primero interinamente y luego de forma regular: fueron los casos de Krause Arnim y de Claps.

En principio, la AGFE contaba con gran autonomía para el manejo de sus gastos corrientes, en tanto que las obras se atendían con fondos de la Tesorería ${ }^{22}$. Pero, como a partir de 1912 comenzó a sobrellevar un déficit de explotación creciente, debió depender de los aportes de la Tesorería no sólo para las nuevas obras, sino también para su propio funcionamiento. La falta de un conocimiento adecuado de los ingresos y gastos, y la demanda de elevadas sumas para diversos rubros provocaron la crítica de la prensa y de la oposición. Los principales debates giraron en torno a la opacidad contable en la rendición de los fondos ${ }^{23}$.

Hasta 1909 la explotación de los Ferrocarriles del Estado había mostrado una rentabilidad positiva y creciente. El viraje se produjo hacia 1910, cuando empezó a funcionar la AGFE, a raíz de las pérdidas que empezaba a experimentar el Central Norte a medida que aumentaba su extensión y del impacto desfavorable de la venta del Andino, en 1909. Todavía las cuentas totales fueron levemente positivas un par de años por las ganancias que aún experimentaba el Argentino del Norte. A partir de 1912 el déficit global fue casi permanente, por la tendencia de los gastos a subir más que el producto. El déficit máximo se alcanzó en 1920-1924, aunque por los disímiles criterios contables que se aplicaron en esos años se hace difícil precisar con exactitud la naturaleza de la situación ${ }^{24}$. En el quinquenio 1925-1929 se logró un descenso significativo del déficit (Cuadro 6).

Respecto a estos magros resultados, parece evidente su correlación con la fuerte ampliación de la red en esos mismos años. La expansión en territorios de escasa

21 El reemplazo de Fernández Beschtedt por Pérez en 1924 no se puede desconectar, a su vez, de las turbulencias que trajo el distanciamiento, a partir de ese año, entre los seguidores del nuevo presidente radical Alvear (el denominado "antipersonalismo") y los de su predecesor. Persello (2004).

22 Entre 1910 y 1917 existen todavía registros en la Contaduría General de la Nación que permiten conocer el movimiento de la explotación. A partir de 1918 la información se encuentra solamente en las estadísticas que elevaba anualmente a la Dirección General de Ferrocarriles.

23 Véase, por ejemplo, La Nación, 2/07/1918; La Prensa, 6/05/1924; y los materiales de la Comisión Especial Investigadora de los Ferrocarriles del Estado que funcionó entre 1923 y 1925. Archivo del Congreso de la Nación, Cámara de Diputados (ACN-CD, en adelante), Paquete 173.

24 Por un lado, la demora en recibir los fondos para algunas obras (Ferrocarril de Huaytiquina) llevó en ciertos momentos a recurrir transitoriamente a los fondos para explotación, sembrando la duda de si esto no se pudo reflejar también en las imputaciones. Por el otro, una investigación contable de 1925 señaló que se habían incluido entre las inversiones algunos rubros (como renovación de materiales y equipo) que por su naturaleza debían haberse cargado a las cuentas de explotación, lo que hubiera hecho aumentar más aún el déficit. Ver Deuda de los Ferrocarriles del Estado al 31 de diciembre de 1924. Informe presentado por el Sr. Contador Nemesio Muntaabski, ACN-CD, paquete 173. 


\section{CUADRO 6}

FERROCARRILES DEL ESTADO: RESULTADOS DE EXPLOTACIÓN, 1895-1929

(promedio anual, pesos oro)

\begin{tabular}{crrrc}
\hline \multicolumn{1}{c}{ Año } & Producto & Gastos & $\begin{array}{c}\text { Ganancias/ } \\
\text { Pérdidas }\end{array}$ & $\begin{array}{c}\text { Coeficiente de } \\
\text { Explotación }\end{array}$ \\
\hline $\mathbf{1 8 9 5 - 1 8 9 9}$ & 1.086 .844 & 1.126 .750 & -39.906 & 1,04 \\
$\mathbf{1 9 0 0 - 1 9 0 4}$ & 2.187 .685 & 1.459 .469 & 728.216 & 0,67 \\
$\mathbf{1 9 0 5 - 1 9 0 9}$ & 4.585 .375 & 3.505 .221 & 1.080 .154 & 0,76 \\
$\mathbf{1 9 1 0 - 1 9 1 4}$ & 6.241 .691 & 6.689 .389 & -447.697 & 1,07 \\
$\mathbf{1 9 1 5 - 1 9 1 9}$ & 9.438 .244 & 9.849 .236 & -410.991 & 1,04 \\
$\mathbf{1 9 2 0 - 1 9 2 4}$ & 16.172 .029 & 17.690 .293 & -1.518 .264 & 1,09 \\
$\mathbf{1 9 2 5 - 1 9 2 9}$ & 24.226 .678 & 24.466 .801 & -240.123 & 1,01 \\
\hline
\end{tabular}

$\left(^{*}\right)$ Para el quinquenio 1918-1923 hemos sumado los resultados de los Ferrocarriles de Fomento y del Ferrocarril del Este, que se publicaban por separado en la Estadística de los Ferrocarriles en Explotación.

Fuentes: Dirección General de Ferrocarriles (1895-1929).

producción generó elevados gastos fijos e ingresos proporcionalmente menores. Por otra parte, la carga transportada era en su mayor parte de gran volumen y bajo valor unitario. Se trataba de productos forestales y materiales para la construcción, que requerían gran cantidad de material rodante y sólo podían soportar módicas tarifas.

En los últimos años, coadyuvó a la mejora de la rentabilidad la disminución en el ritmo de las construcciones, que dio paso al aumento de la producción transportada en las regiones ya servidas, y un seguimiento más estrecho de los gastos operativos y de los mecanismos de control contable. A fines de la presidencia de Alvear (1922-1928), y en el marco de una consolidación general de las deudas de la Administración, se establecieron pautas que apuntaban a resolver definitivamente el problema de la correcta diferenciación entre los gastos corrientes y las inversiones, de un lado, así como entre el nuevo equipamiento y la renovación de instalaciones y material existentes, por el otro. Las turbulencias del final de la década impiden evaluar por ahora debidamente la eficacia de estas medidas ${ }^{25}$.

25 En estos años se regularizó también, mediante un empréstito de consolidación, la copiosa deuda flotante que arrastraban los ferrocarriles desde la primera mitad de los años veinte, debido a los insuficientes fondos recibidos en su momento para las construcciones y la explotación. Ver Informe Muntaabski, ACN-CD, paquete 173. El gobierno de Alvear dispuso una serie de decretos reglamentando las normas contables para poner fin a los problemas que aquejaba a los Ferrocarriles del Estado; véanse los decretos de 27/04/1926, 16/05/1927, 27/12/1927 y 14/06/1928, en BO (ejemplares del 14 de mayo de 1926, 6 de julio de 1927, y 28 de enero y 15de julio de 1928). También Regalsky y Salerno (2003). 


\section{Las inversiones en saneamiento: una experiencia exitosa de empresa pública}

El problema del saneamiento urbano comenzó a plantearse apenas traspuesta la mitad del siglo XIX, y se focalizó por mucho tiempo en la ciudad de Buenos Aires, de lejos la aglomeración de mayor importancia. Aunque las primeras obras destinadas a proveer de agua corriente a la urbe se habilitaron en 1868, un plan integral de saneamiento sólo se adoptó en 1871, diseñado por el ingeniero británico Bateman, en el radio completo que abarcaba entonces la ciudad (y que sería luego conocido como "radio Bateman"). En esa época, las epidemias de cólera (1867) y de fiebre amarilla (1871) contribuyeron a colocar en el centro de la atención pública el problema de la salubridad, aunque lo cierto es que el avance de las ideas del higienismo en las esferas oficiales, así como el ejemplo de las obras de las grandes ciudades europeas y de los Estados Unidos, habían creado el clima de opinión necesario para el desarrollo del emprendimiento ${ }^{26}$.

La habilitación parcial, en 1874, de un establecimiento potabilizador en Recoleta y 90 kilómetros de cañerías, marcó el primer hito. Recién en 1882, cuando se obtuvo nueva financiación externa, se retomó la marcha de las obras (Cuadro 7), hasta que, nuevamente extinguidos los fondos, se adoptó en 1888 la decisión de transferir el servicio a una empresa privada, la Buenos Aires Water Suply and Drainage Company. La corta vida de esta compañía coincidió con un fuerte incremento de la red de agua y la construcción de gran parte de la primera red de cloacas. Sin embargo, las dificultades de financiamiento de la empresa, que llevaron a la crisis al banco involucrado (Baring Brothers), determinaron el retorno de las obras a la esfera estatal. Fue en la nueva etapa, bajo la órbita del Estado, que las obras alcanzarían su mayor despliegue ${ }^{27}$.

La primera etapa de construcción, hasta 1880, estuvo a cargo de una Comisión de Aguas Corrientes, con autonomía relativamente amplia y bajo dependencia directa del gobierno de la Provincia de Buenos Aires. Los intentos previos de dejar la iniciativa a la corporación municipal no habían dado resultado. La federalización de la ciudad de Buenos Aires implicó en 1880 el traspaso a la Nación, quedando a cargo de una Comisión de Obras de Salubridad dependiente del Ministerio del Interior. Nuevas iniciativas se tomaron en la fase privatizadora, que implicaron el cese de la Comisión, el traspaso de la supervisión a la órbita del Departamento de Obras Públi-

\footnotetext{
26 Véanse las contribuciones de Silvestri (2004). Sobre el higienismo y su creciente influencia, Lobato (1996) y González Leandri (1999). También hay referencias a estas cuestiones en casi todas las obras citadas en la nota 23. La principal referencia bibliográfica para el período previo a 1892 es Bordi de Ragucci (1997). Véase también la reseña efectuada por el presidente de la Comisión, el ingeniero Guillermo Villanueva, en Dirección General de Obras de Salubridad de la Nación (1902), así como Baca (1918); Candioti (1918) y, entre los más recientes, Radovanovic, Tartarini y colaboradores (1999), Rey (2003) y Tartarini (2007).
} 


\section{CUADRO 7}

LONGITUD DE CAÑERÍAS DE AGUA Y CLOACAS EN BUENOS AIRES

(metros lineales)

\begin{tabular}{lrcr}
\hline Año & \multicolumn{1}{c}{ Agua } & Cloacas & \multicolumn{1}{c}{ Total } \\
\hline $\mathbf{1 8 7 4}$ & 90.115 & - & 90.115 \\
$\mathbf{1 8 8 2}$ & 97.673 & - & 97.673 \\
$\mathbf{1 8 8 6}$ & 387.075 & - & 387.075 \\
$\mathbf{1 8 8 9}$ & 436.448 & 216.048 & 652.496 \\
$\mathbf{1 8 9 4}$ & 604.822 & 342.852 & 947.674 \\
$\mathbf{1 9 0 2}$ & 927.960 & 376.592 & 1.304 .552 \\
$\mathbf{1 9 0 9}$ & 1.110 .285 & 516.695 & 1.626 .980 \\
$\mathbf{1 9 1 4}$ & 2.234 .418 & 752.393 & 2.986 .811 \\
$\mathbf{1 9 1 7}$ & 3.058 .212 & 1.626 .000 & 4.684 .212 \\
$\mathbf{1 9 2 9}$ & 3.979 .417 & 2.527 .111 & 6.506 .528 \\
\hline
\end{tabular}

Fuentes: Obras Sanitarias de la Nación (1912-1929).

cas del mismo ministerio y, luego, la creación de una Inspección General de las Obras de Salubridad, hasta que la nueva estatalización del servicio en 1891 llevó a la recreación de la Comisión. Sería en el nuevo siglo cuando se adoptaran los cambios que darían al organismo un carácter nacional y mayor autonomía, primero con su transformación, como parte de la organización del Ministerio de Obras Públicas (1898), en Dirección General de Obras de Salubridad de la Nación, y sobre todo, con la ley 8889 de 1912, que crearía las Obras Sanitarias de la Nación, con un directorio con amplias facultades para la administración del servicio.

La conducción del organismo, pese a estas reorganizaciones, mantuvo una notable continuidad, que constituyó una de sus improntas más llamativas en todo el período. Presidida la Comisión por el ingeniero Guillermo Villanueva desde 1891 hasta 1912, excepto un intervalo entre 1895 y 1900 en que lo suplantó el ingeniero Sarhy, con la organización de OSN tomaría su relevo Agustín González, quien, desde 1899, se desempeñaba como Ingeniero Jefe, secundado como vicepresidente por el ingeniero Manuel Ocampo, hasta entonces vocal ${ }^{28}$. Esa generación, por otra parte, 
fue la que diseñó el plan maestro de obras que habría de seguirse de 1910 a 1925 . Hacia 1914, González fue sustituido por el ingeniero, doctor en ciencias físico-matemáticas y exdiputado Marcial Candioti, hasta su retiro en 1925. Entonces asumió la presidencia el ingeniero Pablo Nogués, antiguo Director General de Ferrocarriles, secundado por el ingeniero Máximo Paz, vicepresidente desde 1923 y vocal desde 1921. Al cesar Nogués, en octubre de 1928, por la finalización del gobierno de Alvear y la reasunción de Yrigoyen, asumió Paz como vicepresidente en ejercicio. Significativamente, el golpe de estado que interrumpió en septiembre de 1930 la institucionalidad, no se reflejó en la OSN más que por el ascenso a la presidencia del organismo de quien fuera en los anteriores quince años Director Técnico de la empresa, el ingeniero Antonio Paitoví (Paz continuaría todavía como vicepresidente hasta su retiro). Toda una secuencia de reorganizaciones y ascensos mostraría en esos años el paulatino avance en la carrera burocrática de una serie de ingenieros formados en la empresa.

Las primeras tareas encaradas después del retorno al Estado fueron las de completar las obras entregadas por los concesionarios, así como la introducción de algunas mejoras ${ }^{29}$. A finales de los noventa y a comienzos del nuevo siglo, se fueron añadiendo algunos nuevos distritos, y se instalaron cañerías en Belgrano y Flores (recientemente incorporados al municipio), abastecidos desde pozos semisurgentes. Pronto las provincias empezaron a solicitar del gobierno nacional su apoyo técnico y financiero para la construcción de instalaciones sanitarias en las respectivas capitales, y la Comisión quedó encargada de la supervisión de los proyectos. Hacia 1899, y ante la multiplicación de los pedidos, se dispuso que la nueva Dirección General, además de la supervisión de las obras, quedara a cargo de su administración hasta el reembolso de los fondos adelantados por el gobierno. Sucesivas leyes, en 1900 y 1903, apuntaron a resolver el problema del financiamiento, asignándose el 50 por 100 de las sumas de la Lotería Nacional que correspondían a cada provincia, y finalmente, la emisión de bonos "de las Obras de Salubridad" por parte del gobierno nacional, cuyo servicio sería cargado a las provincias beneficiarias de las obras. Sucesivamente trece de las catorce provincias (con la excepción de la de Buenos Aires) firmaron convenios para la realización de estas obras en sus ciudades capitales, que daban a la Dirección General la potestad de las decisiones en materia de construcción y de fijación de tarifas para el servicio $^{30}$.

29 Entre ellas, la reforma del sistema en el Gran Depósito de la calle Córdoba, construida por los concesionarios.

30 Aún así se incluyó una obra importante en la provincia de Buenos Aires, en la ciudad de Mar del Plata. Entre los casos que se mantuvieron fuera de la jurisdicción de las Obras Sanitarias de la Nación pueden destacarse los de Bahía Blanca y Rosario. En esta última, el servicio fue entregado por concesión a una compañía inglesa desde finales de los años ochenta, y por más de medio siglo. Véase Jones, Jones y Greenhill (1977) y Lanciotti (2007). 
En 1905 se dieron por finalizadas las obras del "Radio Antiguo" de la capital ${ }^{31}$. Proyectadas inicialmente cuando Buenos Aires tenía 200.000 habitantes, y para una población que se habría de duplicar, servían, con todas las mejoras introducidas, a más de 700.000 personas, mostrando signos evidentes de saturación. Se hacía preciso un plan que contemplara también los requerimientos del resto de la capital, en lo que sería llamado el "Radio Nuevo", y que incluía una superficie de 16.000 hectáreas, frente a las 3.000 del antiguo. La concepción de este plan, por otra parte, se conjugaba muy bien con una serie de proyectos que tendían a encauzar el desarrollo urbanístico dentro de moldes racionales y modernos ${ }^{32}$. Entre las obras más significativas se contaban la ampliación del establecimiento Recoleta, la construcción de una segunda, y mucho mayor, planta potabilizadora en Palermo (con su toma de agua propia), dos grandes depósitos distribuidores en Caballito y Devoto, una vasta red de cañerías de suministro de agua y otra más costosa de colectoras cloacales. El sistema se coronaría con la construcción de una Segunda Cloaca Máxima, de $45 \mathrm{Km}$ de extensión, entre el norte de la capital y la localidad de Berazategui, por donde desembocaría en el Río de la Plata, así como de un segundo sifón para su cruce del Riachuelo.

Aunque el plan fue autorizado por la ley 6385 en 1909, los primeros años no fueron de gran dinamismo. El directorio de OSN gestionó durante un largo período la autorización de un empréstito del porte necesario para la magnitud de las obras, que se logró en enero de 1914. Entonces se decidió acelerar la marcha de las obras, al tiempo que el gobierno nacional obtenía en Gran Bretaña dos fuertes adelantos a cuenta de un futuro empréstito que por el estallido de la I Guerra Mundial no se pudo concretar ${ }^{33}$. Así, en 1914 se invirtieron más de 46 millones de pesos y al finalizar 1915 el total invertido superaba los 110 millones. A modo de referencia, las obras completas del radio antiguo, acumuladas en 40 años, se valoraban en 115 millones, y el presupuesto total de las nuevas obras en 168 millones. El estallido de la I Guerra Mundial dejó en suspenso el nuevo empréstito, que debió sustituirse por créditos de corto plazo, reforzados, al menos hasta 1915, por los importantes excedentes líquidos que dejaba la explotación ${ }^{34}$. Después de ese año las obras se fueron desacelerando, y no sólo por el agotamiento de los fondos. Los principales problemas deri-

31 El área estaba delimitada por las calles Billinghurst, Bustamante, Sarmiento, Medrano, Castro Barros, México, Boedo, Carlos Calvo, La Rioja, San Juan, Alberti, Caseros, Brasil, Paseo Colón y Leandro Alem. Rey (2003), p. 34.

32 Liernur y Silvestri (1993) y Gorelik (1998).

33 Los adelantos, inicialmente de 8 millones de libras, se consolidaron en otro de 50 millones de dólares en 1915, equivalente a unos 115 millones de pesos moneda nacional. Véase Peters (1934).

34 En 1914 y 1915 el superávit de la explotación superó los 10 millones de pesos anuales, en tanto que la suma que OSN tenía que entregar para el empréstito por el que se había rescindido la concesión en 1891 era de 4.368.000 pesos. OSN (1914-1915). 
varon de las grandes demoras en el arribo de los materiales y la rescisión de numerosos contratos que no pudieron cumplirse bajo unas condiciones bélicas que la guerra submarina agravó desde 1916. No obstante, las obras fundamentales se fueron habilitando en esos años: las primeras instalaciones de la nueva planta de Palermo, el depósito distribuidor de Caballito y la conexión de Belgrano y Flores con el nuevo sistema de agua superficial tratada en Palermo, en reemplazo de los pozos semisurgentes. Los desagües cloacales tenían un mayor retraso, pero ya se había completado el tramo urbano de la Segunda Cloaca Máxima. La trayectoria de la inversión anual, tras el pico de 1913-1915, fue bajando hasta un mínimo de seis millones de pesos en 1920 (Cuadro 8).

En los años siguientes se fueron completando las restantes obras: el depósito de Villa Devoto, que permitía abastecer a los barrios más alejados, los tramos finales de la Segunda Cloaca Máxima y la habilitación en Palermo de los primeros filtros rápidos. El tendido de cañerías hacia los barrios más alejados pudo encararse a partir del contrato con la firma francesa Pont-a-Mousson, en octubre de 1920, que después de varios años de dilaciones permitió hacer efectiva la compra de 200 kilómetros (unas 20.000 toneladas) de cañerías maestras y distribuidoras.

Mientras tanto, la inversión en las provincias, que hasta 1910 había acumulado más de 30 millones de pesos, fue disminuyendo de año en año, hasta ubicarse en un promedio de 550.000 pesos en 1917-1918. Finalizada la guerra y con la mejora de las finanzas públicas, se sancionó en 1919 la ley 10.998, por la cual se autorizó el estudio, proyecto y construcción de las obras de provisión de agua en todas las ciudades que tuvieran más de 3.000 habitantes, y desagües cloacales en aquéllas que tuvieran más de 8.000, a financiarse con la emisión de bonos. De todos modos, habría que esperar a 1923-1924, cuando se pudieron colocar las primeras emisiones de los títulos internos citados, para que las obras tomaran impulso y llevaran la media anual de inversiones a una cifra próxima a los 9 millones de pesos entre 1925 y 1930.

En cuanto a las obras en la capital, hacia 1925 estaban concluyendo los últimos trabajos relacionados con el plan de 1908, que había insumido hasta esa fecha unos 200 millones de pesos. En 1924, el gobierno nacional presentó en el Congreso el segundo plan maestro de obras, que no llegó a ser tratado por las Cámaras. En su lugar se implementaron sucesivos planes parciales aprobados junto al presupuesto nacional. Las nuevas obras, que comenzaron hacia 1926-1927, apuntaban a asegurar el suministro de agua y desagües, cloacales y pluviales, a una población potencial de 6 millones de habitantes.

Uno de los primeros trabajos fue la construcción de nuevas instalaciones de filtros rápidos en el establecimiento Palermo, con capacidad para producir un millón de metros cúbicos diarios de agua potabilizada, de manera que pudiese quedar fuera de servicio definitivamente el viejo establecimiento Recoleta. Las obras se habilitaron apresuradamente en septiembre de 1928, justo antes de finalizar el presidente 


\section{CUADRO 8}

INVERSIONES DE OSN EN LA CAPITAL Y EN LAS PROVINCIAS, 1911-1934

(en miles de pesos moneda nacional)

\begin{tabular}{lrccrr}
\hline \multicolumn{1}{c}{ Año } & Capital & Porcentajes & Provincias & Porcentajes & Total \\
\hline $\mathbf{1 9 1 1 - 1 9 1 2}$ & 15.956 & 73,0 & 5.893 & 27,0 & 21.850 \\
$\mathbf{1 9 1 3 - 1 9 1 4}$ & 69.725 & 93,5 & 4.876 & 6,5 & 74.602 \\
$\mathbf{1 9 1 5 - 1 9 1 6}$ & 39.408 & 94,6 & 2.255 & 5,4 & 41.663 \\
$\mathbf{1 9 1 7 - 1 9 1 8}$ & 25.543 & 95,6 & 1.171 & 4,4 & 26.715 \\
$\mathbf{1 9 1 1 - 1 9 1 8}$ & 150.632 & 91,4 & 14.195 & 8,6 & 164.830 \\
\hline Promedio anual & $\mathbf{1 8 . 8 2 9}$ & & $\mathbf{1 . 7 7 4}$ & & $\mathbf{2 0 . 6 0 4}$ \\
\hline $\mathbf{1 9 1 9 - 1 9 2 0}$ & 13.354 & 89,1 & 1.638 & 10,9 & 14.992 \\
$\mathbf{1 9 2 1 - 1 9 2 2}$ & 15.805 & 76,6 & 4.821 & 23,4 & 20.625 \\
$\mathbf{1 9 2 3 - 1 9 2 4}$ & 16.411 & 57,1 & 12.338 & 42,9 & 28.749 \\
$\mathbf{1 9 1 9 - 1 9 2 4}$ & 45.570 & 70,8 & 18.797 & 29,2 & 64.366 \\
\hline Promedio anual & $\mathbf{7 . 5 9 5}$ & & $\mathbf{3 . 1 3 3}$ & & $\mathbf{1 0 . 7 2 8}$ \\
\hline $\mathbf{1 9 2 5 - 1 9 2 6}$ & 17.095 & 48,6 & 18.078 & 51,4 & 35.172 \\
$\mathbf{1 9 2 7 - 1 9 2 8}$ & 37.655 & 70,4 & 15.796 & 29,6 & 53.450 \\
$\mathbf{1 9 2 9 - 1 9 3 0}$ & 27.354 & 60,3 & 18.040 & 39,7 & 45.394 \\
$\mathbf{1 9 2 5 - 1 9 3 0}$ & 82.104 & 61,3 & 51.914 & 38,7 & 134.016 \\
\hline Promedio anual & $\mathbf{1 3 . 6 8 4}$ & & $\mathbf{8 . 6 5 2}$ & & $\mathbf{2 2 . 3 3 6}$ \\
\hline $\mathbf{1 9 1 1 - 1 9 3 0}$ & 278.306 & & 84.906 & & 363.212 \\
\hline
\end{tabular}

Fuentes: OSN (1912-1930).

Alvear su mandato, y ese año las inversiones en Buenos Aires alcanzaron los 24 millones de pesos, el monto más alto después de 1914-1915. Al concluir la década de 1920, las principales actividades se concentraban en la construcción de un completo sistema pluvial en el Radio Nuevo, empezando por el entubamiento del arroyo Maldonado, mientras comenzaba a transformarse la red de agua y cloacas de la capital en un sistema que iba a comprender a todo el aglomerado bonaerense.

Un aspecto relevante en el desempeño de esta empresa fue la evolución de los resultados de la explotación (Cuadro 9). En contraste con los Ferrocarriles del Estado, sus resultados arrojaron importantes superávit, al menos dentro del radio capitalino. En la memoria de 1909 se destacaba con orgullo el bajo coeficiente de gastos, del 


\section{CUADRO 9}

OBRAS SANITARIAS DE LA NACIÓN. RESULTADOS DE LA EXPLOTACIÓN

(promedios anuales, en miles de pesos moneda nacional)

\begin{tabular}{|c|c|c|c|c|c|c|c|c|c|c|c|}
\hline \multirow[b]{2}{*}{ Años } & \multicolumn{5}{|c|}{ Capital } & \multicolumn{4}{|c|}{ Provincias } & \multicolumn{2}{|c|}{$\begin{array}{c}\text { Capital / } \\
\text { Provincias }\end{array}$} \\
\hline & (1) & (2) & (3) & (4) & (5) & (1) & (2) & (3) & (4) & (1) & (4) \\
\hline 1905-1909 & 7.184 & 2.542 & 35,4 & 4.642 & 4.683 & $s / d$ & $s / d$ & $s / d$ & $s / d$ & & \\
\hline $1910-1914$ & 12.195 & 3.776 & 31,0 & 8.426 & 4.683 & 1.887 & 1.456 & 77,1 & 431 & 6,5 & 19,5 \\
\hline $1915-1919$ & 16.294 & 8.302 & 50,9 & 7.992 & 4.683 & 2.420 & 2.551 & 105,4 & -131 & 6,7 & \\
\hline $1920-1924$ & 21.921 & 13.624 & 62,2 & 8.297 & $\mathrm{~s} / \mathrm{d}$ & 3.405 & 4.176 & 122,6 & -771 & 6,4 & \\
\hline $1925-1929$ & 36.222 & 15.491 & 42,8 & 20.730 & 20.139 & 5.485 & 4.624 & 84,3 & 862 & 6,6 & 24,1 \\
\hline $\begin{array}{l}\text { (1) Ingresos t } \\
\text { (2) Gastos. } \\
\text { (3) Coeficient } \\
\text { (4) Producto } \\
\text { (5) Servicio d }\end{array}$ & $\begin{array}{l}\text { tales. } \\
\text { de explote } \\
\text { la deuda. }\end{array}$ & ación. & & & & & & & & & \\
\hline
\end{tabular}

Fuentes: OSN (1912-1930).

33,81 por 100 "proporción que no alcanza ninguna de las empresas de ferrocarriles, ni otras análogas, en nuestro país y muy pocas en el extranjero" ${ }^{\prime 35}$. Con todo, recién en 1907 el producto neto había alcanzado la suma necesaria para atender los gastos de intereses y amortización del empréstito de 1892, con el que se había estatalizado de nuevo el servicio, y los bonos de la ley 4158.

Como indicamos más arriba, la progresión ascendente del producto neto siguió hasta 1914 y 1915, en que alcanzó los 10 millones de pesos. Desde 1916, y más aún desde 1918, los gastos tendieron a subir más que los ingresos y, en consecuencia, el producto neto quedó durante 10 años por debajo de los valores de 1914-1915. El coeficiente de gastos se ubicó por encima del 60 por 100. Hacia 1925, con la gestión rigurosa del ingeniero Nogués, los gastos se pudieron contener. Simultáneamente, la reciente habilitación de numerosas conexiones domiciliarias por las nuevas obras en la capital y en las provincias permitieron una aceleración en el crecimiento de los ingresos, de modo que el coeficiente de explotación bajó hasta cerca del 40 por 100, y el producto neto ascendió, en 1925-1929, hasta un nivel ubicado un 150 por 100 por encima del de 1910-1914.

35 Dirección General de Obras de Salubridad de la Nación (1906-1909), p. 93. 
Por entonces, los gastos financieros, que debían atenderse con esos recursos, habían subido enormemente. De los 4,6 millones que representaban los empréstitos de las Obras Sanitarias antes de 1914, se llegó en 1927 a superar los 20 millones, un monto muy similar al producto neto disponible. En ello influían los empréstitos externos con los que, en 1924-1925 y en 1927, se habían consolidado los adelantos recibidos tempranamente para la realización de las obras, y, en menor medida, los títulos de deuda interna que los sucesivos presupuestos venían autorizando a colocar. En la práctica, esto recortaba la autonomía del organismo, ya que si bien podía asegurar la explotación sin recursos externos, necesitaba de los fondos de la Tesorería para todos sus programas de inversión.

La explotación de las Obras en las provincias merece una mención aparte. Habiendo sido hasta 1924 deficitaria, comenzó a arrojar saldos positivos desde 1925, por la contención de los gastos a los que nos referimos previamente. Sin embargo, los coeficientes de explotación siempre fueron sensiblemente mayores que los de la capital (del orden del 80 por 100 en este último período) y, por otra parte, el monto de ingresos brutos que la totalidad de las ciudades aportaba era seis veces inferior al que generaba la ciudad de Buenos Aires. Con la habilitación de los primeros servicios en las ciudades y pueblos comprendidos en la ley 10.998, un nuevo problema comenzó a cernirse sobre el futuro: el carácter deficitario de la explotación en estas localidades más pequeñas, cuya incidencia no haría más que crecer a medida que se completaran las obras. Esto, de todos modos, habría de impactar en otra etapa histórica, en la que muchos de los elementos del contexto en el que se desenvolvió el organismo serían sustancialmente diferentes.

\section{Consideraciones finales}

En los tres primeros decenios del siglo XX se asistió al surgimiento de los primeros casos duraderos de empresas públicas en la Argentina, que habrían de subsistir hasta las grandes privatizaciones de los años noventa. Correspondieron a la fase final del Estado liberal, que por cierto estuvo imbuido de un activismo económico, particularmente en el área de servicios básicos e infraestructura, como en pocas oportunidades se volvería a encontrar en el período posterior a 1930. El contexto fue de crecimiento casi continuo - sólo interrumpido por los efectos de la Gran Guerra- en el gasto y la inversión pública, así como de la magnitud del aparato estatal. Precisamente el sentido de estos emprendimientos, que tuvieron sus orígenes en el último tercio del siglo XIX, fue el de afirmar la presencia del Estado nacional en todo el territorio, y garantizar una serie de servicios básicos o bienes públicos (transporte, agua potable) a toda la comunidad. Desde ese punto de vista pueden considerarse como 
parte del proceso de formación y ampliación del Estado nacional que, con distintos ropajes, no detuvo su marcha desde mediados del siglo XIX hasta, cuando menos, la mitad de la centuria siguiente.

El desempeño de los organismos analizados presenta una serie de rasgos comunes, a la vez que matices diferenciales y a veces contrastantes. Así se encuentra un notable paralelismo en lo que respecta al momento de su creación y a las marchas y contramarchas que se plantean respecto de la acción directa del Estado (privatizaciones a finales del decenio de 1880 y nuevas nacionalizaciones a comienzos del de 1890). Lo mismo se puede observar en relación al momento de gestación de los grandes proyectos de inversión, en los primeros años del siglo XX, reflejo en parte de la bonanza imperante en las finanzas públicas, pero también de un consenso sobre las esferas de la acción pública que habría de mantenerse más allá de la I Guerra Mundial, y de los cambios que contemporáneamente se produjeron en el escenario político argentino.

No obstante, en esta fase se observa una secuencia diferencial entre ambas instituciones: el grueso de las construcciones ferroviarias se acometió más tempranamente, y se interrumpió hacia 1914, mientras que las de saneamiento en la urbe porteña, iniciadas más tardíamente, prosiguieron en pleno conflicto bélico. Del mismo modo, la reactivación de las obras ferroviarias se produjo en la década de los veinte, aunque se iba a restringir severamente en la segunda mitad de la misma, precisamente cuando las obras de saneamiento volvieron a tomar mayor intensidad, esta vez con un peso más elevado de las provincias. Sin duda, fue el efecto de cruzadas influencias: la relación estado central-poderes provinciales (un campo fructífero que nos resta aún por explorar) y los efectos del variado desempeño económico de ambas entidades.

En efecto, donde se encuentra un cuadro más contrastante es en el desempeño económico y los resultados financieros de la explotación: los mediocres rendimientos de los ferrocarriles, agudizados con la privatización de la única sección rentable, derivaron en permanentes déficit operativos de la flamante Administración, que terminarían por interferir — a mediados de los años veinte- en la continuidad de los propios programas de inversión. Ésta era la otra cara de una acción pública que avanzaba en la construcción de una red ferroviaria sobre territorios que se hallaban fuera del radio de interés de las compañías privadas, pero cuya pobreza productiva entrañaba rendimientos financieros que no alcanzaba a sufragar los costos de la operación. Queda claro que el Estado estaba priorizando, más allá de la rentabilidad mínima, la función social de proveer las infraestructuras necesarias para facilitar el comercio y la movilidad de las personas en esas regiones apartadas.

En tanto, las obras de saneamiento, concentradas por mucho tiempo en la ciudad de Buenos Aires, presentaron una elevada rentabilidad operativa que permitió, 
incluso, sufragar el costo de su ingente endeudamiento, tanto el resultante de la breve etapa privada (en los años ochenta del siglo XIX) como el de la segunda época estatal. Orientadas a proveer en la urbe porteña un servicio que la administración municipal no se hallaba en condiciones de garantizar, a diferencia de lo ocurrido en otras ciudades europeas y de los Estados Unidos, extendieron sus actividades -a partir de comienzos del siglo XX y nuevamente en la década de 1920- a las ciudades del interior del país. La instalación de servicios sanitarios, bajo el control de una administración centralizada, se fue expandiendo, con una lógica similar a la observada en el caso ferroviario, hasta los parajes más alejados. Ciertamente que aquí también los ingresos comenzaban a revelarse insuficientes, pero se compensaban con los percibidos en un área central que en el caso de los transportes ferroviarios se hallaba bajo control privado.

Finalmente, el examen de estos dos casos nos permite también apreciar la temprana articulación de una burocracia técnica conformada por los ingenieros de cada sector (ferroviarios y sanitarios), que fueron ocupando los cargos técnicos y gerenciales, e interviniendo en el diseño y la ejecución de los planes elaborados. No ocurriría lo mismo con la alta dirección, que en el caso de los Ferrocarriles del Estado habría de padecer una constante inestabilidad, e incluso intervenciones contables, por los malos resultados financieros, que pondrían entre paréntesis el grado de autonomía alcanzado como empresa. En tanto en las Obras Sanitarias de la Nación, su mejor desempeño garantizaría una mayor estabilidad en la conducción de su dirección, que trascendería incluso la ruptura institucional de 1930, y unos mecanismos de promoción normalizados al interior de sus cuadros técnicos superiores. Los márgenes de autonomía tropezarían también aquí, fatalmente, con restricciones, en la medida en que el elevado endeudamiento había terminado por absorber los importantes excedentes generados, manteniendo su dependencia del poder central para la consecución de las nuevas obras.

\section{Fuentes}

Archivo del Congreso de la Nación, Cámara de Diputados (ACN-CD, Buenos Aires), Comisión Especial Investigadora de los Ferrocarriles del Estado (1923 y 1925), Paquete 173 (39 folios).

Archivo Central Ferroviario (ACF-AGFE, Buenos Aires), Actas del Consejo de Administración de los Ferrocarriles del Estado (1910-1930).

Museo Nacional Ferroviario, Archivo de la Dirección General de Ferrocarriles (ADGF, Buenos Aires). 


\section{Bibliografía}

ADMINISTRACIÓN GENERAL DE LOS FERROCARRILES DEL ESTADO (19281931): Itinerario de Trenes, Buenos Aires.

BACA, Eduardo J. (1918): Las obras de salubridad de la Ciudad de Buenos Aires, Buenos Aires, Librería Las Ciencias.

Boletín Oficial de la República Argentina, 1912-1930.

BORDI DE RAGUCCI, Olga (1997): El agua privada en Buenos Aires, 1856-1892, Buenos Aires, Vinciguerra.

BOTANA, Natalio R. (1998): El orden conservador: la política argentina entre 1880 y 1916, Buenos Aires, Sudamericana.

CANDIOTI, Marcial R. (1918): Cincuentenario de las obras de la Capital Federal: exposición sobre su desarrollo económico y financiero 1868-1918, Buenos Aires, Establecimiento Gráfico A. de Martino.

CASTANO, Arturo (1914): Finanzas de los Ferrocarriles Argentinos, Buenos Aires, Imprenta Cúneo.

COMÍN, Francisco, y DÍAZ FUENTES, Daniel (2004): La empresa pública en Europa, Una perspectiva histórica, Madrid, Síntesis.

COMÍN, Francisco, y MARTÍN ACEÑA, Pablo (1991) (dirs.): Historia de la empresa pública en España, Madrid, Espasa Calpe.

CONTADURÍA GENERAL DE LA NACIÓN (1912-1929): Memoria, Buenos Aires.

CORTÉS CONDE, Roberto (1989): Dinero, deuda y crisis. Evolución fiscal y monetaria en la Argentina, Buenos Aires, Sudamericana.

-(1997): La economía argentina en el largo plazo. Ensayos de historia económica (siglos XIX y XX), Buenos Aires, Sudamericana y Universidad de San Andrés.

-(2005): La economía politica de la Argentina en el siglo XX, Buenos Aires, Edhasa.

DEPARTAMENTO DE OBRAS PÚBLICAS (1885-1888): Memoria, Buenos Aires, Ministerio de Interior.

DÍAZ ALEJANDRO, Carlos (1975): Ensayos de historia económica argentina, Buenos Aires, Amorrortu.

DÍAZ FUENTES, Daniel (1994): Crisis y cambios estructurales en América Latina. Argentina, Brasil y México durante el período de entreguerras, México, Fondo de Cultura Económica.

DIRECCIÓN DE INFORMACIONES Y PUBLICACIONES FERROVIARIAS (1946): Origen y desarrollo de los Ferrocarriles Argentinos, Buenos Aires, El Ateneo.

DIRECCIÓN DE LOS FERROCARRILES NACIONALES (1891): Memoria de los Ferrocarriles Nacionales, Buenos Aires.

DIRECCIÓN GENERAL DE FERROCARRILES (1892-1930): Estadística de los Ferrocarriles en Explotación, Buenos Aires. 
DIRECCIÓN GENERAL DE OBRAS DE SALUBRIDAD DE LA NACIÓN (18991911): Memorias presentadas a SE el Sr. Ministro de Obras Públicas por el Director General, Buenos Aires.

FLORIA, Carlos, y GARCÍA BELSUNCE, Horacio (1995): Historia de los Argentinos, Buenos Aires, Kapelusz.

FOREMAN-PECK, James, y MILLWARD, Robert (1994): Public and private ownership of British industry, Oxford, Clarendon Press.

GADANO, Nicolás (2006): Historia del petróleo en la Argentina, 1907-1955: Desde los inicios hasta la caída de Perón, Buenos Aires, Edhasa.

GERCHUNOFF, Pablo, y LLACH, Lucas (2003): El ciclo de la ilusión y el desencanto. Un siglo de politicas económicas argentina, Buenos Aires, Ariel.

GONZÁLEZ LEANDRI, Ricardo (1999): Curar, persuadir, gobernar. La construcción histórica de la profesión médica en Buenos Aires, Madrid, Consejo Superior de Investigaciones Científicas.

GORELIK, Adrián (1998): La grilla y el parque: espacio público y cultura urbana en Buenos Aires, 1887-1936, Buenos Aires, Universidad Nacional de Quilmes.

HASSAN, John (1995): “The water industry 1900-51: a failure of public policy?", en MILLWARD, Robert, y SINGLETON, John (eds.), The political economy of nationalisation in Britain 1920-1950, Cambridge, Cambridge University Press, pp. 189210.

JONES, Charles; JONES, Linda, y GREENHILL, Robert (1977): “Public Utility Companies", en PLATT, Desmond C.M. (ed.), Business Imperialism 1840-1930, Oxford, Oxford University Press, pp. 77-118.

La Nación, 1910-1930.

La Prensa, 1910-1930.

LACOSTE, Pablo (2000): El Ferrocarril Trasandino, 1872-1984, Santiago de Chile, Editorial Universitaria y Centro de Investigaciones Barros Arana.

LANCIOTTI, Norma (2007): “Empresas autónomas y grupos de inversión. Las empresas del grupo Morrison en Rosario, Argentina. (1890-1930)", Investigaciones de Historia Económica, 8, pp. 109-140.

LEWIS, Colin M. (1983): British railways in Argentina 1857-1914. A case study of foreign investment, London, Institute of Latin American Studies, University of London.

LIERNUR, Jorge F., y SILVESTRI, Graciela (1993): El umbral de la metrópolis: transformaciones técnicas y cultura en la modernización de Buenos Aires, 1870-1930, Buenos Aires, Sudamericana.

LOBATO, Mirta (comp.) (1996): Politica, médicos y enfermedades: lecturas de historia de la salud Argentina, Buenos Aires, Biblos.

LÓPEZ, Mario J. (1991): Historia de los Ferrocarriles de la Provincia de Buenos Aires, Buenos Aires, Ediciones Lumière. 
-(1994): Historia de los Ferrocarriles Nacionales, Buenos Aires, Ediciones Lumière.

-(2000): Ferrocarriles Deuda y Crisis. Historia de los Ferrocarriles en la Argentina de 1887 a 1896, Buenos Aires, Editorial de Belgrano.

MARICHAL, Carlos (1988): “Políticas de desarrollo económico y deuda externa en Argentina (1868-1880)", Siglo XIX. Revista de Historia, III, 5, pp. 89-124.

MINISTERIO DE HACIENDA (1900-1911): Memoria, Buenos Aires.

MINISTERIO DE OBRAS PÚBLICAS (1898-1930): Memoria, Buenos Aires.

MUSTAPIC, Ana María (1984): “Conflictos institucionales durante el primer gobierno radical. 1916-1922", Desarrollo Económico, Revista de Ciencias Sociales, 93, vol. 24, abril-junio, pp. 85-108.

OBRAS SANITARIAS DE LA NACIÓN (1912-1934): Memoria, Buenos Aires.

ORTIZ, Ricardo M. (1946): El ferrocarril en la economía argentina, Buenos Aires, Problemas.

OSZLAK, Oscar (1982): La formación del Estado Argentino, Buenos Aires, Editorial de Belgrano.

PALERMO, Silvana (2001): “The Nation Building Mission: The State-Owned Railways in Modern Argentina (1870-1930)", Tesis doctoral inédita, St. University of N. York at Stony Brook.

PERSELLO, Ana Virginia (2004): El partido radical. Gobierno y oposición, 1916-1943, Buenos Aires, Siglo XXI Editores Argentina.

PETERS, Harold Edwin (1934): The Foreign Debt of the Argentine Republic, Baltimore, John Hopkins University Studies in Historical and Political Science.

PRETTO, Raúl U. (1926): Ferrocarriles del Estado. Formación y desarrollo de la red, Buenos Aires, Ministerio de Obras Públicas, Dirección General de Ferrocarriles.

RADOVANOVIC, Elisa; TARTARINI, Jorge D., y colaboradores (1999): Agua y saneamiento en Buenos Aires, 1580-1930. Riqueza y singularidad de un patrimonio, Buenos Aires, Aguas Argentinas.

RAMALLO, Carlos (1930): Los Ferrocarriles del Estado en la Argentina, Buenos Aires, Imprenta de la Universidad.

REGALSKY, Andrés M. (1998): "Endeudamiento, finanzas públicas y balanza de pagos. El caso argentino, 1880-1914", Public debt, public finance, money and balance of payments in debtor countries 1890-1932/33. 12 International Economic History Congress. Session B16, Sevilla, pp. 165-176.

-(2002): Mercados, inversores y élites: las inversiones francesas en la Argentina, 18801914, Buenos Aires, Universidad Nacional de Tres de Febrero.

REGALSKY, Andrés, y SALERNO, Elena (2005): “En los comienzos del Estado empresario: la inversión pública en ferrocarriles y obras sanitarias entre 1900 y 1928", Anuario del Centro de Estudios Históricos "Prof. Segretti", 5, pp. 247-272.

-(2007): "Mercados de capitales, desarrollo ferroviario y endeudamiento público. 
La financiación de los ferrocarriles del Estado, 1916-1928", en SCHVARZER, Jorge; REGALSKY, Andrés y GÓMEZ, Teresita (comps.), Estudio sobre la historia de los ferrocarriles argentinos, Universidad de Buenos Aires, Buenos Aires, pp. 153-188.

REY, Osvaldo (2003): El saneamiento en el área metropolitana. Desde el Virreinato a 1993, Buenos Aires, Aguas Argentinas.

Registro Nacional (1889-1907), Buenos Aires.

ROCK, David (1975): El radicalismo argentino, 1890-1930, Buenos Aires, Amorrortu.

SALERNO, Elena (2003): Los comienzos del Estado empresario: la Administración General de los Ferrocarriles del Estado (1910-1928), Buenos Aires, CEEED-UBA.

SCALABRINI ORTIZ, Raúl (1986 [1957]): Historia de los ferrocarriles argentinos, Buenos Aires, Plus Ultra.

SCHVARZER, Jorge (1979): "Empresas públicas y desarrollo industrial en Argentina", Economía de América Latina, 3, pp. 45-68.

SCHVARZER, Jorge, y GÓMEZ, Teresita (2006): La primera gran empresa de los argentinos. El Ferrocarril del Oeste (1854-1862), Buenos Aires, Fondo de Cultura Económica.

SILVESTRI, Graciela (2004): "Obras de Saneamiento", en LIERNUR, Jorge F., y ALIATA, Fernando (eds.), Diccionario de arquitectura en la Argentina: estilos, obras, biografias, instituciones, ciudades, Buenos Aires, Clarín/Arquitectura, Tomo O-R, pp. 12-16.

SOARES, Carlos F. (1932): Economía y finanzas de la Nación Argentina, 1916-1932, Buenos Aires, Rodríguez Giles.

SOLBERG, Carl E. (1982): Petróleo y Nacionalismo en la Argentina, Buenos Aires, Editorial Emecé.

TARTARINI, Jorge D. (2007) (coord.): Obras Sanitarias de la Nación, 1912-1950. Origen y apogeo de la primera empresa estatal de saneamiento, Buenos Aires, AYSA.

TOPIK, Steven (1987): The Political Economy of the Brazilian State, 1889-1930, Austin, Texas University Press.

ZALDUENDO, Eduardo A. (1975): Libras y Rieles. Las inversiones británicas para el desarrollo de los ferrocarriles en Argentina, Brasil, Canadá e India durante el Siglo XIX, Buenos Aires, El Coloquio.

ZIMMERMANN, Eduardo (1995): Los liberales reformistas. La cuestión social en la Argentina, 1890-1916, Buenos Aires, Sudamericana y Universidad de San Andrés. 
ANEXO 1

LOS PRESIDENTES ARGENTINOS, 1862-1930

\begin{tabular}{ll}
\hline Período & \multicolumn{1}{c}{ Presidente } \\
\hline $1862-1868$ & Bartolomé Mitre \\
$1868-1874$ & Domingo Faustino Sarmiento \\
$1874-1880$ & Nicolás Avellaneda \\
$1880-1886$ & Julio Argentino Roca \\
$1886-1890$ & Miguel Ángel Juárez Celman (renuncia) \\
$1890-1892$ & Carlos Pellegrini (vicepresidente a cargo de la Presidencia) \\
$1892-1895$ & Luis Sáenz Peña (renuncia) \\
$1895-1898$ & José Evaristo Uriburu (vicepresidente a cargo de la Presidencia) \\
$1898-1904$ & Julio Argentino Roca \\
$1904-1906$ & Manuel Quintana (fallecimiento) \\
$1906-1910$ & José Figueroa Alcorta (vicepresidente a cargo de la Presidencia) \\
$1910-1914$ & Roque Sáenz Peña (fallecimiento) \\
$1914-1916$ & Victorino de la Plaza (vicepresidente a cargo de la Presidencia) \\
$1916-1922$ & Hipólito Yrigoyen \\
$1922-1928$ & Marcelo T. de Alvear \\
$1928-1930$ & Hipólito Yrigoyen (destituido por golpe de Estado)
\end{tabular}

Fuentes: Floria y García Belsunce (1995). 
ANEXO 2

FERROCARRILES DEL ESTADO EN 1931

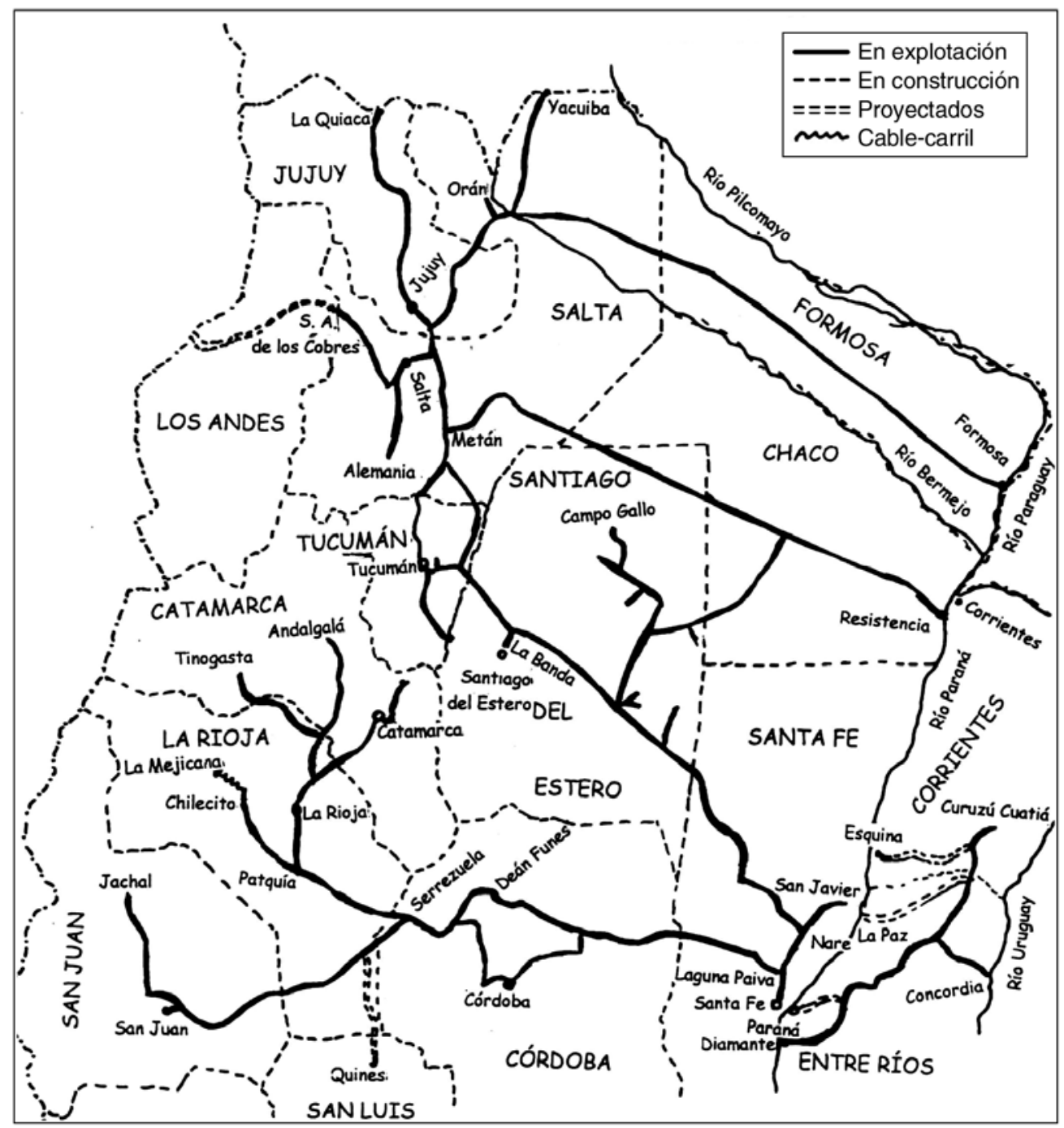

Fuentes: Administración General de los Ferrocarriles del Estado (1928-1931). 


\section{ANEXO 3}

FERROCARRILES DEL ESTADO EN LA PATAGONIA EN 1931

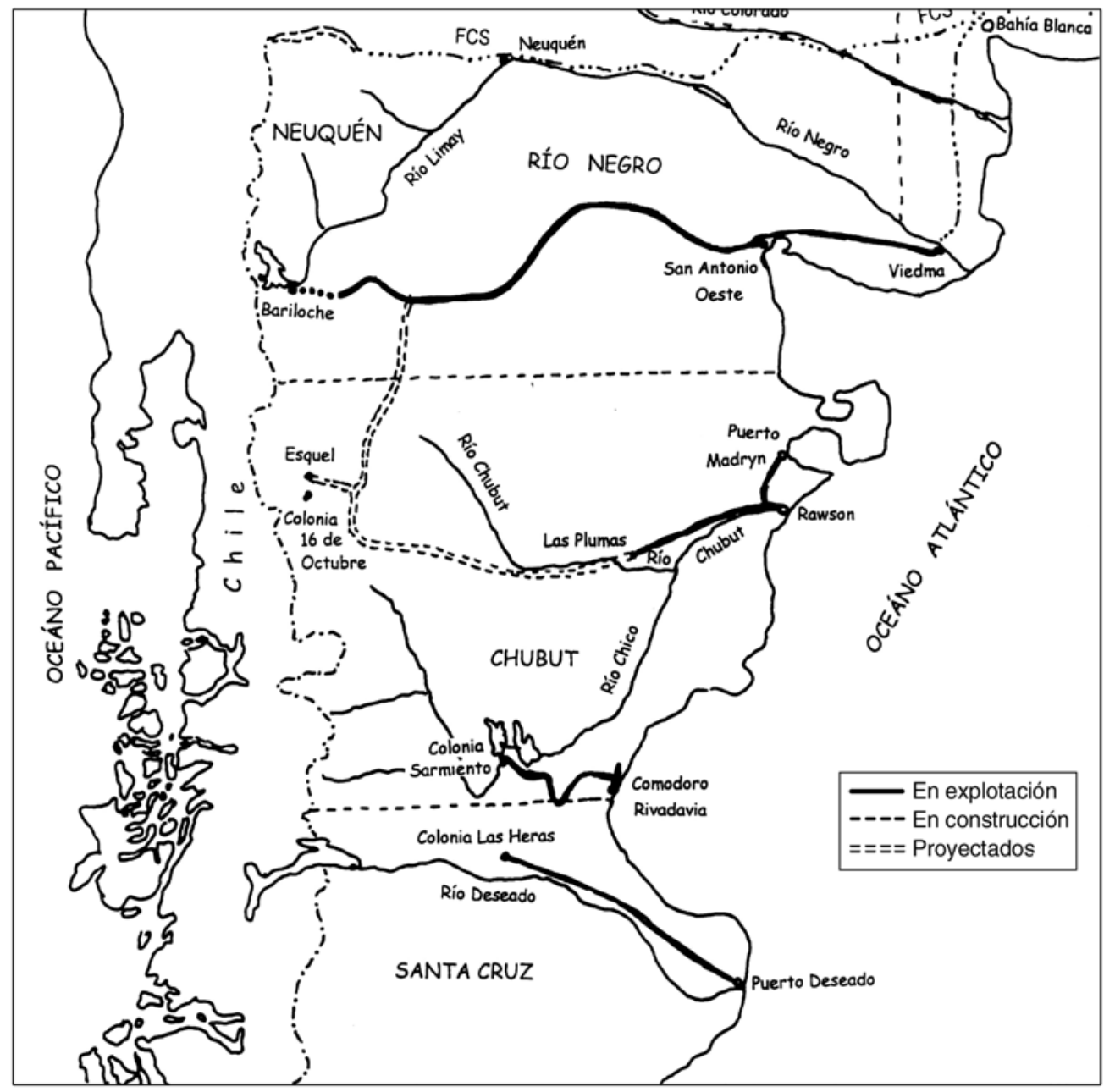

Fuentes: Administración General de los Ferrocarriles del Estado (1928-1931). 